\title{
RNA-based CRISPR-Mediated Loss-of-Function Mutagenesis in Human Pluripotent Stem Cells
}

\section{Leung, Alan W.}

2020-06-12

Leung , A W , Broton , C , Bogacheva , M S , Xiao , A Z , Garcia-Castro , M I \& Lou , Y-R 2020 , ' RNA-based CRISPR-Mediated Loss-of-Function Mutagenesis in Human Pluripotent

Stem Cells ' , Journal of Molecular Biology , vol. 432 , no. 13 , pp. 3956-3964 . https://doi.org/10.1016/j.jmb.2020.04.

http://hdl.handle.net/10138/329373

https://doi.org/10.1016/j.jmb.2020.04.017

cc_by_nc_nd

acceptedVersion

Downloaded from Helda, University of Helsinki institutional repository.

This is an electronic reprint of the original article.

This reprint may differ from the original in pagination and typographic detail.

Please cite the original version. 


\section{Journal Pre-proof}

RNA-based CRISPR-Mediated Loss-of-Function Mutagenesis in Human Pluripotent Stem Cells

Alan W. Leung, Cayla Broton, Mariia S. Bogacheva, Andrew Z. Xiao, Martin I. Garcia-Castro, Yan-Ru Lou

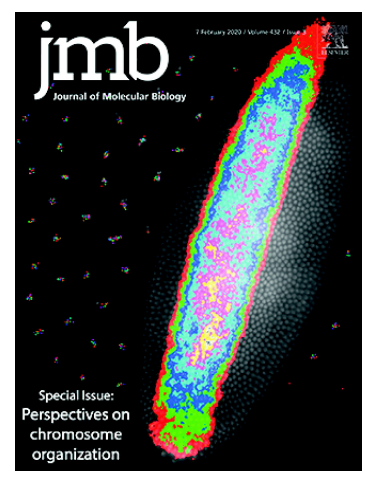

PII: S0022-2836(20)30305-3

DOI: https://doi.org/10.1016/j.jmb.2020.04.017

Reference:

YJMBI 66523

To appear in: Journal of Molecular Biology

Received date: 19 February 2020

Revised date: 7 April 2020

Accepted date: 19 April 2020

Please cite this article as: A.W. Leung, C. Broton, M.S. Bogacheva, et al., RNA-based CRISPR-Mediated Loss-of-Function Mutagenesis in Human Pluripotent Stem Cells, Journal of Molecular Biology (2020), https://doi.org/10.1016/j.jmb.2020.04.017

This is a PDF file of an article that has undergone enhancements after acceptance, such as the addition of a cover page and metadata, and formatting for readability, but it is not yet the definitive version of record. This version will undergo additional copyediting, typesetting and review before it is published in its final form, but we are providing this version to give early visibility of the article. Please note that, during the production process, errors may be discovered which could affect the content, and all legal disclaimers that apply to the journal pertain.

(C) 2020 Published by Elsevier. 
Title

RNA-based CRISPR-Mediated Loss-of-Function Mutagenesis in Human Pluripotent Stem Cells

\section{Authors}

Alan W. Leung ${ }^{1,2}$, Cayla Broton ${ }^{2,3,6}$, Mariia S. Bogacheva, ${ }^{4,6}$, Andrew Z. Xiao ${ }^{1,2}$, Martin I. GarciaCastro $^{5}$, Yan-Ru Lou ${ }^{4, *}$

\section{Affiliations}

${ }^{1}$ Yale Stem Cell Center, ${ }^{2}$ Department of Genetics, 214A Amistad Building, Yale University

${ }^{3}$ Department of Molecular, Cellular and Developmental Biology, Yale University

${ }^{4}$ Division of Pharmaceutical Biosciences, Faculty of Pharmacy, University of Helsinki, Helsinki, Finland

${ }^{5}$ School of Medicine Division of Biomedical Sciences, University of California, Riverside, CA 92521, USA

${ }^{6}$ co-second authors

*Correspondence:

Yan-Ru Lou: yan-ru.lou@helsinki.fi

Running Title

RNA-based CRISPR in Human Pluripotent Stem Cells 


\begin{abstract}

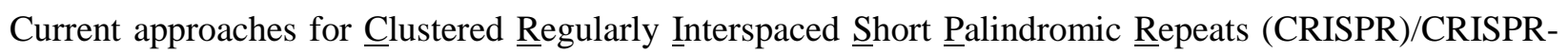
Associated-9 (Cas9)-mediated genome editing in human pluripotent stem (PS) cells mainly employ plasmids or ribonucleoprotein complexes. Here, we devise an improved transfection protocol of in vitro transcribed $\operatorname{Cas} 9$ mRNA and crRNA:tracrRNA duplex that can effectively generate indels in four genetic loci (two active and two inactive) and demonstrate utility in four human PS cell lines (one embryonic and three induced PS cell lines). Our improved protocol incorporating a Cas9-linked selection marker and a staggered transfection strategy promotes targeting efficiency up to $85 \%$ and biallelic targeting efficiency up to $76.5 \%$ of total mutant clones. The superior targeting efficiency and the non-integrative nature of our approach underscores broader applications in high-throughput arrayed CRISPR screening and in generating custom-made or off-the-shelf cell products for human therapy.
\end{abstract}

Graphical abstract

\title{
Keywords
}

Clustered Regularly Interspaced Short Palindromic Repeats, Cas9 messenger RNA, crRNA:tracrRNA duplex, transfection, lipofection 


\section{Introduction}

Using the CRISPR platform it is found that human PS cell populations, like human primary cells, consistently displayed from at least 2 up to 5 folds less targeting events than immortalized human cell lines, such as HEK293T and K562 (1,2). With a plasmid-based schematic where DNA plasmids delivered the $\operatorname{Cas} 9$ transgene and single-guide RNAs, human PS cell populations could be edited with an efficiency ranging from 2 to $4 \%$ of non-homologous end joining (NHEJ) events in the actively transcribed AAVS1 locus (2). Enriching human PS cells that were transiently expressing Cas9 plasmid through antibiotic selection or flow cytometry resulted in enhanced NHEJ-mediated targeting events to $50 \%$ or more $(3,4)$. Biallelic targeting efficiency however still ranged only from $<10 \%$ to around $20 \%(3,5)$. To promote biallelic targeting efficiency in human PS cells, cell lines with inducible or constitutive Cas9 expression were constructed and they yielded biallelic knockout efficiencies ranging from $20 \%$ to $60 \%$, depending on gene targets (6). This latter approach however requires the generation of parent human PS cells with Cas9 transgene integrated into the genome.

Cas9 RNP has been successfully delivered into human PS cells or other in vitro cell lines using lipofection, electroporation, nucleofection, or virus-like particles (1,7-12). The targeting efficiency mediated by Cas9 RNP varied among different studies and was highly dependent on the delivery methods. A most recent study found that introduction of Cas 9 protein and chemically modified guide RNA into human PS cells by electroporation and a delayed delivery of an adenovirus donor template led to an efficient homology directed repair rate and a biallelic targeting efficiency ranging from $10 \%$ to $74 \%$ depending on the targeting loci (13). This method however results in elevated off-target frequency ( $90 \%)$ of the top two off-targets. The use of a high-fidelity Cas9 protein appears to reduce off-target events but sacrifices biallelic targeting efficiency (reduced from $76 \%$ to $20 \%$ ) and shifts the majority of the mutations instead to monoallelic (13).

As an alternative approach to Cas9 RNP, Cas9 and its variants had been introduced as mRNA species together with a plasmid expressing sgRNA and episomal reprogramming factors into human fibroblasts by electroporation to simultaneously generate human induced PS (iPS) cells and to knock-in 
EGFP gene into the DNMT3B gene locus. The resulting human iPS cells displayed 52\% of EGFP knockin efficiency and $>60 \%$ of these knock-in clones had both alleles modified (14). Of the rest of the EGFPnegative clones, $90 \%$ contained indels in both alleles (14), a targeting efficiency equivalent or even superior to the Cas9 RNP approach. This targeting efficiency however may reflect targeting events that occurred in reprogramming human fibroblasts prior to the establishment of stable human iPS cells. On the other hand, this high efficiency could be due to efficient delivery of Cas9 mRNA into human cells by electroporation and the use of a sgRNA plasmid that allowed stable expression of sgRNA for efficient gene editing as it was suggested that sgRNA became labile without the presence of circulating Cas9 protein $(15,16)$. Cas 9 mRNA and synthetic sgRNA had also been directly introduced into human PS cells by simple transfection in an attempt to edit the Emxl locus. The resultant efficiency as detected by the semi-quantitative T7 endonuclease assay appeared to be quite low (17). The lack of extensive transfection and targeting efficiency data with Cas9 mRNA mediated genome editing in human PS cells highlights the need for this study and further protocol optimization and standardization in large mRNA species delivery into human PS cells and ways to control gRNA stability.

To achieve these goals, we aim to develop an improved RNA transfection method coupled with antibiotic selection for CRISPR-mediated mutagenesis in human PS cells.

\section{Results}

Enhanced Targeting Efficiency of Cas9 Messenger RNAs Through Coupled Antibiotic Selection and a

\section{$\underline{\text { Staggered Delivery Protocol }}$}

Cas 9 mRNA delivery in single cell suspension consistently resulted in $50 \%$ or fewer of the transfected cells expressing Cas9 protein (Fig. S1E, S3D). We reasoned that targeting efficiency could be further promoted if we incorporated a selection step for Cas9-expressing cells. We therefore cloned an antibiotic selection marker gene, puromycin N-acetyl-transferase (Pac), linked by a self-cleaving Thoseaasigna virus 2A (T2A) peptide sequence (18), to the downstream of the Cas 9 mRNA. We first demonstrated that Pac gene was functional by transfecting Cas 9 or Cas9-T2A-Pac mRNAs into human PS cells and applied puromycin to transfected cells (data not shown). A previous study suggested that 
guide RNAs introduced into human cells were susceptible to degradation (15). We speculated that introducing $\operatorname{Cas} 9$ mRNA prior to the crRNA:tracrRNA duplexes would increase the circulating amount of translated Cas9 proteins to interact with the newly transfected crRNA:tracrRNA duplexes. We therefore designed the following experimental conditions in an attempt to optimize our approach to maximize targeting efficiency (Fig. 1A): Condition A (co-lipofection), the same as the condition shown in Supplementary data (Fig. S5), consisted of Cas9 mRNA co-transfecting with the crRNA:tracrRNA duplexes simultaneously; Condition B (co-lipofection + antibiotic selection) consisted of Cas9-T2A-Pac mRNA co-transfecting alongside the crRNA:tracrRNA duplexes with subsequent puromycin antibiotic selection overnight; Condition C (staggered lipofection + antibiotic selection) consisted of Cas9-T2A-Pac mRNA delivery preceding transfection of the crRNA:tracrRNA duplexes by 4 hours, and antibiotic selection was performed thereafter for 24 hours. An interval of 4 hours between first (Cas 9 mRNA) and second (crRNA:tracrRNA duplex) delivery was chosen because we observed the percentage of Cas $9^{+}$ protein peaked at 4 hours after Cas 9 mRNA transfection (Fig. S3D). For condition C, after the first transfection, cells were seeded at non-clonal densities to preserve cell survival. Unlike most previous studies that examine the targeting efficiency in a bulk population, under all conditions, cells were seeded after the first (conditions A and B) or second (condition C) transfection at clonal densities to mimic an actual targeting experiment and harvested after clonal expansion for genotyping.

To test these different conditions, we designed a guide RNA targeting a sequence shortly after the translation start site of a differentiation gene, alpha-fetoprotein (AFP) (Fig. 1B). AFP is a serum protein secreted from fetal liver and yolk sac, and is re-expressed in hepatocellular carcinomas, but is not expressed in human ES and iPS cells. We selected AFP gene because we wanted to test the efficiency of our approach on a locus containing a differentiation gene which only expresses during differentiation and may contain highly condensed chromatin structures. After clonal expansion of transfected GM23720B human iPS cells, we screened 40 to 90 clones by Sanger sequencing for each of the three conditions (corresponding to experiments 6,7 , and 8 in Table 1). In order to more accurately assess targeting events that RFLP was prone to omit, as well as to simultaneously deduce the type of mutations, we employed 
Tracking of Indels by Decomposition (TIDE) analysis (19). TIDE analysis utilizes a decomposition algorithm to identify major mutations from a projected guide RNA-targeting site on sequence traces obtained by Sanger sequencing. Targeting efficiency predicted by TIDE analysis has been shown to be more accurate than the commonly used T7 endonuclease assay, and is closest to those determined by deep sequencing (20). To quantify targeting efficiencies for AFP targeting under the 3 conditions, TIDE analysis outputs from wildtype (Fig. 1C), monoallelic (Fig. 1E), biallelic (Fig. 1D), and mixed (indicates non-clonal populations, Fig. $1 \mathrm{~F}$ ) clones were categorized according to their mutation types as displayed in Tables S2, S3, and S4 for conditions A, B, and C, respectively. As expected, we detected increasing frequency of total mutant clones obtained under co-lipofection only (29.17\%), co-lipofection + antibiotic selection (47.19\%), and staggered lipofection + antibiotic selection (67.44\%) conditions, demonstrating that antibiotic selection (co-lipofection + antibiotic selection vs co-lipofection only) and earlier introduction of $\operatorname{Cas} 9$ mRNA (staggered lipofection + antibiotic selection vs co-lipofection + antibiotic selection) promoted CRISPR-mediated NHEJ events in GM23720B human iPS cells (Fig. 1G). Earlier introduction of Cas 9 mRNA species, i.e., staggered lipofection + antibiotic selection (condition C), reversed the trend of inducing a majority of monoallelic mutant clones under co-lipofection only (condition A) and co-lipofection + antibiotic selection (condition B) conditions to promoting biallelic targeting events to close to half of the total targeting events (Fig. 1G) (48.84\% of the total clones or $72.41 \%$ of the edited clones, experiment 8 in Table 1).

To confirm that the targeting events indeed resulted in the loss of protein function, we first differentiated the parent GM23720B cells, an isogenic wildtype (C18) clone, and a knockout (C21) clone into fetal hepatocytes by following our published protocol (21) and then performed western blot analysis to detect the expression of AFP protein. Proteins from human liver cancer cell line HepG2 were used as positive control in western blot analysis. We detected the $69 \mathrm{kDa}$ AFP protein expression in the HepG2 cells, the isogenic wildtype C18 cells, and the parent GM23720B cells, but not in the C21 knockout cells (Fig. 1H). 
To examine if the improved staggered transfection + antibiotic selection approach resulted in any off-target effects, we examined by PCR followed by Sanger sequencing of six of the top predicted offtarget exonic regions (OT1 to OT6) targeted by the AFP guide RNA. We found no modifications in all regions examined in the clonal AFP isogenic wildtype (C18) and knockout (C21) cell lines (Fig. S6).

\section{Improved RNA-based CRISPR Method Mediated Efficient Multiplex crRNA Targeting}

To verify this improved staggered transfection plus antibiotic selection protocol and test if this method could accommodate multiplex targeting experiments to facilitate larger deletions, we devised a dual-guide RNA approach. To this end, we designed two crRNAs $\sim 250$ base pairs apart that targeted the second exon of FOXB1 (Fig. 2A). We first transfected Cas9-T2A-Pac mRNA, and, 4 hours later, transfected the two crRNA:tracrRNA duplexes, as outlined in condition C (Fig. 1A). We performed this experiment on two different cell lines: WA01 ES and Y6 iPS cells. For WA01, up to 75\% of the clones $(\mathrm{n}=54$, out of 72$)$ contained at least a 250 base pair deletion in one of the two alleles (Fig. 2B) (Experiment 9 in Table 1). Among these mutant clones, 44.4\% (24 clones or 33.3\% when all the clones were taken into account) were shown to be biallelic for the expected deletion. All of these biallelic clones were confirmed by Sanger sequencing as containing only deletions without the presence of wildtype allele. Western blotting performed on differentiating cells from 3 selected FOXB1 knockout and isogenic cell lines confirmed that the expression of FOXB1 proteins was abolished (22). Similarly, for the Y6 cell line, we observed up to $85 \%$ (17 out of 20 clones) targeting efficiency, with up to $76.5 \%$ (13 of the edited clones or $65 \%$ of the total clones) displaying biallelic deletions (Fig. 2C) (Experiment 10 in Table 1). Biallelic deletion efficiency varies from $33.3 \%$ to $65 \%$ between the two PS cell lines we have tested for this multiplex approach (Fig. 2D). Lastly, using this staggered transfection plus antibiotic selection approach, we successfully generated double knockout of FOXB1 and GBX2 using 4 pairs of crRNAs that

respectively targeted the DNA binding domains of these transcription factors in a single targeting experiment (Fig. 2E, F, n=1/48, 2.1\%). The targeting efficiency for the same pair of FOXB1 crRNAs, however, was lower than the previous experiment that targeted only the FOXB1 locus $(\mathrm{n}=13 / 48,27 \%$ in 
Experiment 11 compared to $75 \%$ in Experiment 9). This suggests that delivery of increasing number of crRNA:tracrRNA duplexes might have hindered the targeting efficiency of individual crRNAs.

\section{Discussion}

Using our RNA-based delivery platform, we have accomplished editing efficiency ranging from $5 \%$ up to $30 \%$ (of total clones) in human PS cells without the use of any selection markers - an efficiency similar to that previously reported for Cas9 RNP in human ES cells (1). With the introduction of our staggered delivery protocol coupled with antibiotic selection, we augmented total targeting efficiency up to $85 \%$ and biallelic targeting efficiency between $\sim 30 \%$ and $\sim 70 \%$ in multiple genetic loci in different human PS cell lines. This biallelic targeting efficiency is as efficient as that reported with an inducible Cas9 genome-integrated cell line (6) and comparable to that with a high-fidelity mutant of Cas9 protein with superior on-target efficiency in human hematopoietic progenitors (23). Our targeting efficiency is superior to plasmid-based methods with transient selection markers $(3,5)$ and is generally higher than that observed when Cas9 RNP was co-delivered with chemically modified guide RNA molecules in human PS cells (13). Our current data therefore serve as a proof-of-concept experiment for efficient CRISPRmediated genome editing in human PS cells via lipofection using in vitro transcribed Cas 9 mRNA and chemically synthesized crRNA:tracrRNA duplexes, and serve as a non-integrative alternative to Cas9 RNP method for genome editing in human PS cells.

In vivo delivery of Cas9 and other mRNA species has wide applications in many therapeutic areas, for instance, systemic delivery or local administration of Cas 9 and other mRNAs assisted by lipidbased nanoparticles or other biocompatible formulations has been used to rescue disease phenotypes in animal models of human diseases such as myocardial infarction (24), heart injury (25), and other inborn genetic errors such as Factor IX deficiency (26,27), methylmalonic acidemia (28), familial hypercholesterolemia (29), and hereditary tyrosinemia (30). For in vitro research, delivery of in vitro synthesized messenger RNA has been employed as a strategy to engineer lymphocytes to target human mesothelin expression, which is associated with poor prognosis, for pre-clinical CART cell therapy in a mouse solid tumor model for ovarian cancer (31). Messenger RNA transfection has been used to direct 
differentiation of human PS cells $(32,33)$ and to reprogram adult somatic cells into human PS cells (14,17,33). GFP and Cas9 mRNAs have been transfected with lipo-based reagent into human PS cells but with no reported statistics on transfection efficiency (17). Using our modified transfection protocol that takes advantage of the increased survival of single human PS cells in the presence of the Rho kinase inhibitor $(34,35)$, we are able to achieve transfection efficiency of reporter gene and $\operatorname{Cas} 9$ mRNAs in multiple cell lines from $\sim 50 \%$ up to $90 \%$ and over, depending on the mRNA species. For disease modeling, our method can be used to generate cell lines with the removal of specific genetic sequences targeting neurodegenerative diseases such as myotonic dystrophy type 1 and 2 (DM1/2), Huntington's disease, and C9orf72-linked amyotrophic lateral sclerosis (C9-ALS) associated with microsatellite nucleotide repeat expansion (36,37). Lastly, as our method is integration-free, it can be readily applied to preclinical research on genome editing applications involving generation of patient or "off-the-shelf" iPS cell lines.

\section{Additional details}

The additional Results, detailed Materials and Methods, and additional Acknowledgement can be found in Supplementary data published online.

\section{Author contributions}

AWL conceived, designed, and supervised the research, performed the experiments on WA01 ES and Y6 iPS cell lines, analyzed the data, and wrote the manuscript. Y-RL supervised and performed experiments on GM23720B and GM25256B iPS cells and edited the manuscript. CB assisted in the drafting and revision of the manuscript. MSB and $\mathrm{CB}$ performed experiments on genotyping and optimizing the protocols. AZX, MIGC, and Y-RL secured essential resources and funds to support this study.

\section{Acknowledgement}

This work was supported by CT Innovations and University of Helsinki.

\section{References}


1. Kim, S., Kim, D., Cho, S.W., Kim, J. and Kim, J.S. (2014) Highly efficient RNA-guided genome editing in human cells via delivery of purified Cas9 ribonucleoproteins. Genome Res, 24, 1012-1019.

2. Mali, P., Yang, L., Esvelt, K.M., Aach, J., Guell, M., DiCarlo, J.E., Norville, J.E. and Church, G.M. (2013) RNA-Guided Human Genome Engineering via Cas9. Science, 339, 823826.

3. Ran, F.A., Hsu, P.D., Wright, J., Agarwala, V., Scott, D.A. and Zhang, F. (2013) Genome engineering using the CRISPR-Cas9 system. Nat Protoc, 8, 2281-2308.

4. Steyer, B., Bu, Q., Cory, E., Jiang, K., Duong, S., Sinha, D., Steltzer, S., Gamm, D., Chang, Q. and Saha, K. (2018) Scarless Genome Editing of Human Pluripotent Stem Cells via Transient Puromycin Selection. Stem Cell Reports, 10, 642-654.

5. Ding, Q., Regan, S.N., Xia, Y., Oostrom, L.A., Cowan, C.A. and Musunuru, K. (2013) Enhanced efficiency of human pluripotent stem cell genome editing through replacing TALENs with CRISPRs. Cell Stem Cell, 12, 393-394.

6. Gonzalez, F., Zhu, Z., Shi, Z.D., Lelli, K., Verma, N., Li, Q.V. and Huangfu, D. (2014) An iCRISPR platform for rapid, multiplexable, and inducible genome editing in human pluripotent stem cells. Cell stem cell, 15, 215-226.

7. Liang, X., Potter, J., Kumar, S., Zou, Y., Quintanilla, R., Sridharan, M., Carte, J., Chen, W., Roark, N., Ranganathan, S. et al. (2015) Rapid and highly efficient mammalian cell engineering via Cas9 protein transfection. Journal of Biotechnology, 208, 44-53.

8. Lin, S., Staahl, B.T., Alla, R.K. and Doudna, J.A. (2014) Enhanced homology-directed human genome engineering by controlled timing of CRISPR/Cas9 delivery. eLife, $\mathbf{3}$, e04766.

9. Liu, J., Gaj, T., Yang, Y., Wang, N., Shui, S., Kim, S., Kanchiswamy, C.N., Kim, J.-S. and Barbas Iii, C.F. (2015) Efficient delivery of nuclease proteins for genome editing in human stem cells and primary cells. Nat. Protocols, 10, 1842-1859.

10. Ramakrishna, S., Kwaku Dad, A.-B., Beloor, J., Gopalappa, R., Lee, S.-K. and Kim, H. (2014) Gene disruption by cell-penetrating peptide-mediated delivery of Cas 9 protein and guide RNA. Genome Research.

11. Liang, X., Potter, J., Kumar, S., Ravinder, N. and Chesnut, J.D. (2017) Enhanced CRISPR/Cas9-mediated precise genome editing by improved design and delivery of gRNA, Cas9 nuclease, and donor DNA. J Biotechnol, 241, 136-146.

12. Lyu, P., Javidi-Parsijani, P., Atala, A. and Lu, B. (2019) Delivering Cas9/sgRNA ribonucleoprotein (RNP) by lentiviral capsid-based bionanoparticles for efficient 'hit-and-run' genome editing. Nucleic Acids Res, 47, e99.

13. Martin, R.M., Ikeda, K., Cromer, M.K., Uchida, N., Nishimura, T., Romano, R., Tong, A.J., Lemgart, V.T., Camarena, J., Pavel-Dinu, M. et al. (2019) Highly Efficient and Markerfree Genome Editing of Human Pluripotent Stem Cells by CRISPR-Cas9 RNP and AAV6 Donor-Mediated Homologous Recombination. Cell Stem Cell, 24, 821-828 e825.

14. Howden, S.E., McColl, B., Glaser, A., Vadolas, J., Petrou, S., Little, M.H., Elefanty, A.G. and Stanley, E.G. (2016) A Cas9 Variant for Efficient Generation of Indel-Free Knockin or Gene-Corrected Human Pluripotent Stem Cells. Stem Cell Reports, 7, 508517.

15. Hendel, A., Bak, R.O., Clark, J.T., Kennedy, A.B., Ryan, D.E., Roy, S., Steinfeld, I., Lunstad, B.D., Kaiser, R.J., Wilkens, A.B. et al. (2015) Chemically modified guide RNAs 
enhance CRISPR-Cas genome editing in human primary cells. Nat Biotechnol, 33, 985-989.

16. Ma, H., Tu, L.C., Naseri, A., Huisman, M., Zhang, S., Grunwald, D. and Pederson, T. (2016) CRISPR-Cas9 nuclear dynamics and target recognition in living cells. J Cell Biol, 214, 529-537.

17. Kehler, J., Greco, M., Martino, V., Pachiappan, M., Yokoe, H., Chen, A., Yang, M., Auerbach, J., Jessee, J., Gotte, M. et al. (2017) RNA-Generated and Gene-Edited Induced Pluripotent Stem Cells for Disease Modeling and Therapy. J Cell Physiol, 232, 1262-1269.

18. Kim, J.H., Lee, S.R., Li, L.H., Park, H.J., Park, J.H., Lee, K.Y., Kim, M.K., Shin, B.A. and Choi, S.Y. (2011) High cleavage efficiency of a 2A peptide derived from porcine teschovirus-1 in human cell lines, zebrafish and mice. PLoS One, 6, e18556.

19. Brinkman, E.K., Chen, T., Amendola, M. and van Steensel, B. (2014) Easy quantitative assessment of genome editing by sequence trace decomposition. Nucleic Acids Res, 42, e168.

20. Sentmanat, M.F., Peters, S.T., Florian, C.P., Connelly, J.P. and Pruett-Miller, S.M. (2018) A Survey of Validation Strategies for CRISPR-Cas9 Editing. Sci Rep, 8, 888.

21. Kanninen, L.K., Harjumaki, R., Peltoniemi, P., Bogacheva, M.S., Salmi, T., Porola, P., Niklander, J., Smutny, T., Urtti, A., Yliperttula, M.L. et al. (2016) Laminin-511 and laminin-521-based matrices for efficient hepatic specification of human pluripotent stem cells. Biomaterials, 103, 86-100.

22. Leung, A.W., López-Giráldez, F., Broton, C., Lin, K., Prasad, M.S., Hernández, J.C., Xiao, A.Z. and Garcia-Castro, M.I. (2019) Pre-Border Gene Foxb1 Regulates the Differentiation Timing and Autonomic Neuronal Potential of Human Neural Crest Cells. bioRxiv.

23. Vakulskas, C.A., Dever, D.P., Rettig, G.R., Turk, R., Jacobi, A.M., Collingwood, M.A., Bode, N.M., McNeill, M.S., Yan, S., Camarena, J. et al. (2018) A high-fidelity Cas9 mutant delivered as a ribonucleoprotein complex enables efficient gene editing in human hematopoietic stem and progenitor cells. Nat Med, 24, 1216-1224.

24. Carlsson, L., Clarke, J.C., Yen, C., Gregoire, F., Albery, T., Billger, M., Egnell, A.C., Gan, L.M., Jennbacken, K., Johansson, E. et al. (2018) Biocompatible, Purified VEGF-A mRNA Improves Cardiac Function after Intracardiac Injection 1 Week Postmyocardial Infarction in Swine. Mol Ther Methods Clin Dev, 9, 330-346.

25. Sultana, N., Magadum, A., Hadas, Y., Kondrat, J., Singh, N., Youssef, E., Calderon, D., Chepurko, E., Dubois, N., Hajjar, R.J. et al. (2017) Optimizing Cardiac Delivery of Modified mRNA. Mol Ther, 25, 1306-1315.

26. Ramaswamy, S., Tonnu, N., Tachikawa, K., Limphong, P., Vega, J.B., Karmali, P.P., Chivukula, P. and Verma, I.M. (2017) Systemic delivery of factor IX messenger RNA for protein replacement therapy. Proc Natl Acad Sci U S A, 114, E1941-E1950.

27. Li, B., Luo, X., Deng, B., Wang, J., McComb, D.W., Shi, Y., Gaensler, K.M., Tan, X., Dunn, A.L., Kerlin, B.A. et al. (2015) An Orthogonal Array Optimization of Lipid-like Nanoparticles for mRNA Delivery in Vivo. Nano Lett, 15, 8099-8107.

28. An, D., Schneller, J.L., Frassetto, A., Liang, S., Zhu, X., Park, J.S., Theisen, M., Hong, S.J., Zhou, J., Rajendran, R. et al. (2017) Systemic Messenger RNA Therapy as a Treatment for Methylmalonic Acidemia. Cell Rep, 21, 3548-3558. 
29. Yin, H., Song, C.Q., Suresh, S., Wu, Q., Walsh, S., Rhym, L.H., Mintzer, E., Bolukbasi, M.F., Zhu, L.J., Kauffman, K. et al. (2017) Structure-guided chemical modification of guide RNA enables potent non-viral in vivo genome editing. Nat Biotechnol, 35, 1179-1187.

30. Yin, H., Song, C.Q., Dorkin, J.R., Zhu, L.J., Li, Y., Wu, Q., Park, A., Yang, J., Suresh, S., Bizhanova, A. et al. (2016) Therapeutic genome editing by combined viral and nonviral delivery of CRISPR system components in vivo. Nat Biotechnol, 34, 328-333.

31. Hung, C.F., Xu, X., Li, L., Ma, Y., Jin, Q., Viley, A., Allen, C., Natarajan, P., Shivakumar, R., Peshwa, M.V. et al. (2018) Development of Anti-Human Mesothelin-Targeted Chimeric Antigen Receptor Messenger RNA-Transfected Peripheral Blood Lymphocytes for Ovarian Cancer Therapy. Hum Gene Ther, 29, 614-625.

32. Wang, X.L., Yu, L., Ding, Y., Guo, X.R., Yuan, Y.H. and Li, D.S. (2015) Gene Manipulation of Human Embryonic Stem Cells by In Vitro-Synthesized mRNA for Gene Therapy. Curr Gene Ther, 15, 428-435.

33. Warren, L., Manos, P.D., Ahfeldt, T., Loh, Y.H., Li, H., Lau, F., Ebina, W., Mandal, P.K., Smith, Z.D., Meissner, A. et al. (2010) Highly efficient reprogramming to pluripotency and directed differentiation of human cells with synthetic modified mRNA. Cell Stem Cell, 7, 618-630.

34. Ma, Y., Jin, J., Dong, C., Cheng, E.C., Lin, H., Huang, Y. and Qiu, C. (2010) Highefficiency siRNA-based gene knockdown in human embryonic stem cells. RNA, 16, 2564-2569.

35. Ohgushi, M., Matsumura, M., Eiraku, M., Murakami, K., Aramaki, T., Nishiyama, A., Muguruma, K., Nakano, T., Suga, H., Ueno, M. et al. (2010) Molecular pathway and cell state responsible for dissociation-induced apoptosis in human pluripotent stem cells. Cell Stem Cell, 7, 225-239.

36. Dastidar, S., Ardui, S., Singh, K., Majumdar, D., Nair, N., Fu, Y., Reyon, D., Samara, E., Gerli, M.F.M., Klein, A.F. et al. (2018) Efficient CRISPR/Cas9-mediated editing of trinucleotide repeat expansion in myotonic dystrophy patient-derived iPS and myogenic cells. Nucleic Acids Res, 46, 8275-8298.

37. van Agtmaal, E.L., Andre, L.M., Willemse, M., Cumming, S.A., van Kessel, I.D.G., van den Broek, W., Gourdon, G., Furling, D., Mouly, V., Monckton, D.G. et al. (2017) CRISPR/Cas9-Induced (CTGCAG)n Repeat Instability in the Myotonic Dystrophy Type 1 Locus: Implications for Therapeutic Genome Editing. Mol Ther, 25, 24-43.

\section{Figure legends}

Fig. 1. Improved CRISPR targeting efficiency with antibiotic selection and a modified lipofection protocol. (A) Testing different transfection and antibiotic selection protocols (experimental conditions A, $\mathrm{B}$, and C) for targeting experiments using Cas9/Cas9-T2A-Pac mRNA and AFP-crRNA:tracrRNA complex. (B) Targeting strategy on human AFP locus. (C-F) Examples of TIDE analysis results of wildtype and different types of mutant clones derived from GM23720B human iPS cells. (G) Chart showing the proportion of monoallelic and biallelic mutant clones, and clones with more than 2 alleles 
(mixed clones) under experimental conditions A, B, and C from transfected GM23720B cells. (H) Since AFP is expressed in fetal liver and liver cancer, but not in human iPS cells, to assess whether AFP locus is disrupted by our CRISPR method, we first differentiated the parent GM23720B cells, an isogenic wildtype $\mathrm{C} 18$ clone, and a biallelic knockout C21 clone for 18 days to generate fetal hepatocytes. Western blot analysis of AFP expression was performed in the derived fetal hepatocytes and a positive control human liver cancer cell line HepG2. A single band at $69 \mathrm{kDa}$ was detected in HepG2, fetal hepatocytes derived from GM23720B cells, and fetal hepatocytes derived from wildtype C18 cells, but not in fetal hepatocytes derived from biallelic knockout C21 cells.

Fig. 2. Multiplex targeting using the staggered lipofection protocol. (A) Targeting strategy on human FOXB1 locus using 2 crRNAs. (B-C) PCR genotyping results of individual clones harvested from WA01 ES cells and Y6 iPS cells transfected with Cas9-T2A-Pac mRNA and 2 FOXB1-crRNA:tracrRNA complexes as shown in panel A. Condition $\mathrm{C}$ in Figure 1 was employed. M: marker lane. +: positive control. Blue bold case: monoallelic truncation/deletion. Red bold case: biallelic truncation/deletion. (D) Chart showing the proportion of monoallelic and biallelic truncation mutant clones summarized from data presented in panels B and C. $\mathrm{n}$ indicates total number of clones harvested. (E) Targeting strategy on human GBX2 locus using 2 crRNAs. (F) PCR genotyping results of an isogenic wildtype (clone \#2) and a double FOXB $1^{--} G B X 2^{-/-}$knockout clone (clone \#1). 
Table 1. Experimental details and summary statistics for the CRISPR-targeting experiments performed in this study

\begin{tabular}{|c|c|c|c|c|c|c|c|c|c|}
\hline $\begin{array}{l}\text { Exp } \\
\text {. }\end{array}$ & Locus & Cell line & $\begin{array}{l}\text { crRNA } \\
\text { :tracrRN } \\
\text { A duplex }\end{array}$ & $\begin{array}{l}\text { Cas9 species } \\
\text { and } \\
\text { lipofection } \\
\text { method }\end{array}$ & $\begin{array}{l}\text { Clones } \\
\text { harveste } \\
\text { d }\end{array}$ & $\begin{array}{l}\text { Clones } \\
\text { successful } \\
\text { ly } \\
\text { screened } \\
\end{array}$ & $\begin{array}{l}\text { Screeni } \\
\text { ng } \\
\text { strategy }\end{array}$ & $\begin{array}{l}\text { Targeting } \\
\text { efficiency } \\
1, \%[\mathrm{~N}]\end{array}$ & $\begin{array}{l}\text { Biallelic } \\
\text { targeting } \\
\text { efficiency } \\
2, \%[\mathrm{~N}] \\
\end{array}$ \\
\hline 1 & $\begin{array}{l}\text { FOXB } \\
1\end{array}$ & $\begin{array}{l}\text { WA01 } \\
\text { ESC }\end{array}$ & Single & $\begin{array}{l}\text { Co-lipofection } \\
\text { of Cas9 } \\
\text { mRNA \& } \\
\text { crRNA:tracrR } \\
\text { NA }\end{array}$ & 72 & 58 & $\begin{array}{l}\text { RFLP \& } \\
\text { Sanger } \\
\text { seq }\end{array}$ & $6.90[4]$ & nd \\
\hline 2 & $\begin{array}{l}\text { FOXB } \\
1\end{array}$ & $\begin{array}{l}\text { WA01 } \\
\text { ESC }\end{array}$ & Single & $\begin{array}{l}\text { Co-lipofection } \\
\text { of Cas9 } \\
\text { protein \& } \\
\text { crRNA:tracrR } \\
\text { NA }\end{array}$ & 64 & 60 & $\begin{array}{l}\text { RFLP \& } \\
\text { Sanger } \\
\text { seq }\end{array}$ & $3.33[2]$ & nd \\
\hline 3 & PHC2 & $\begin{array}{l}\text { WA01 } \\
\text { ESC }\end{array}$ & Single & $\begin{array}{l}\text { Co-lipofection } \\
\text { of Cas9 } \\
\text { mRNA \& } \\
\text { crRNA:tracrR } \\
\text { NA }\end{array}$ & 96 & 95 & $\begin{array}{l}\text { RFLP \& } \\
\text { Sanger } \\
\text { seq }\end{array}$ & $3.16[3]$ & nd \\
\hline 4 & $P H C 2$ & $\begin{array}{l}\text { GM25256 } \\
\text { B iPSC }\end{array}$ & Single & $\begin{array}{l}\text { Co-lipofection } \\
\text { of Cas9 } \\
\text { mRNA \& } \\
\text { crRNA:tracrR } \\
\text { NA }\end{array}$ & 53 & 53 & $\begin{array}{l}\text { RFLP \& } \\
\text { Sanger } \\
\text { seq }\end{array}$ & $3.77[2]$ & nd \\
\hline 5 & PHC2 & $\begin{array}{l}\text { GM23720 } \\
\text { B iPSC }\end{array}$ & Single & $\begin{array}{l}\text { Co-lipofection } \\
\text { of Cas9 } \\
\text { mRNA \& } \\
\text { crRNA:tracrR } \\
\text { NA }\end{array}$ & 100 & 100 & $\begin{array}{l}\text { RFLP \& } \\
\text { Sanger } \\
\text { seq }\end{array}$ & $5.00[5]$ & nd \\
\hline 6 & $A F P$ & $\begin{array}{l}\text { GM23720 } \\
\text { B iPSC }\end{array}$ & Single & $\begin{array}{l}\text { Co-lipofection } \\
\text { of Cas9 } \\
\text { mRNA \& } \\
\text { crRNA:tracrR } \\
\text { NA }\end{array}$ & 84 & 72 & $\begin{array}{l}\text { PCR \& } \\
\text { Sanger } \\
\text { seq }\end{array}$ & $\begin{array}{l}29.17 \\
{[21]}\end{array}$ & $8.33[6]$ \\
\hline 7 & $A F P$ & $\begin{array}{l}\text { GM23720 } \\
\text { B iPSC }\end{array}$ & Single & $\begin{array}{l}\text { Co-lipofection } \\
\text { of Cas9-T2A- } \\
\text { Pac mRNA \& } \\
\text { crRNA:tracrR } \\
\text { NA plus } \\
\text { selection }\end{array}$ & 89 & 89 & $\begin{array}{l}\text { PCR \& } \\
\text { Sanger } \\
\text { seq }\end{array}$ & $\begin{array}{l}47.19 \\
{[42]}\end{array}$ & $5.62[5]$ \\
\hline 8 & $A F P$ & $\begin{array}{l}\text { GM23720 } \\
\text { B iPSC }\end{array}$ & Single & $\begin{array}{l}\text { Staggered } \\
\text { lipofection of } \\
\text { Cas9-T2A-Pac } \\
\text { mRNA \& } \\
\text { crRNA:tracrR } \\
\text { NA plus } \\
\text { selection }\end{array}$ & 44 & 43 & $\begin{array}{l}\text { PCR \& } \\
\text { Sanger } \\
\text { seq }\end{array}$ & $\begin{array}{l}67.44 \\
{[29]}\end{array}$ & $\begin{array}{l}48.84 \\
{[21]}\end{array}$ \\
\hline 9 & $\begin{array}{l}\text { FOXB } \\
1\end{array}$ & $\begin{array}{l}\text { WA01 } \\
\text { ESC }\end{array}$ & Double & $\begin{array}{l}\text { Staggered } \\
\text { lipofection of }\end{array}$ & 72 & 72 & PCR & $\begin{array}{l}75.00 \\
{[54]}\end{array}$ & $\begin{array}{l}33.33 \\
{[24]} \\
\end{array}$ \\
\hline
\end{tabular}




\begin{tabular}{|c|c|c|c|c|c|c|c|c|c|}
\hline & & & & $\begin{array}{l}\text { Cas9-T2A-Pac } \\
\text { mRNA \& } \\
\text { crRNA:tracrR } \\
\text { NA plus } \\
\text { selection }\end{array}$ & & & & & \\
\hline 10 & $\begin{array}{l}\text { FOXB } \\
1\end{array}$ & Y6 iPSC & Double & $\begin{array}{l}\text { Staggered } \\
\text { lipofection of } \\
\text { Cas9-T2A-Pac } \\
\text { mRNA \& } \\
\text { crRNA:tracrR } \\
\text { NA plus } \\
\text { selection }\end{array}$ & 20 & 20 & PCR & $\begin{array}{l}85.00 \\
{[17]}\end{array}$ & $\begin{array}{l}65.00 \\
{[13]}\end{array}$ \\
\hline 11 & $\begin{array}{l}\text { FOXB } \\
1 \\
\text { GBX2 }\end{array}$ & $\begin{array}{l}\text { WA01 } \\
\text { ESC }\end{array}$ & $\begin{array}{l}\text { Quadrup } \\
\text { le }\end{array}$ & $\begin{array}{l}\text { Staggered } \\
\text { lipofection of } \\
\text { Cas9-T2A-Pac } \\
\text { mRNA \& } \\
\text { crRNA:tracrR } \\
\text { NA plus } \\
\text { selection }\end{array}$ & 48 & 41 & PCR & $\begin{array}{l}31.71 \\
{[13]-} \\
\text { FOXB1 } \\
4.88[2]- \\
\text { GBX2 }\end{array}$ & $\begin{array}{l}17.07[7] \\
-F O X B 1 \\
4.88[2]- \\
\text { GBX2 }\end{array}$ \\
\hline
\end{tabular}

${ }^{1}$ Percentage of mutated clones out of total number of screened clones. Confirmed by Sanger sequencing and/or PCR genotyping. Numbers in brackets indicate the number of clones identified as mutants. Targeting efficiencies for experiments 9 to 11 represent percentage of clones with at least one allele containing a large deletion as detected by PCR genotyping ${ }^{2}$ Biallelic targeting efficiency was deduced by TIDE analysis and PCR genotyping for experiments 6-8 and 9-11 respectively. Numbers in brackets indicate the number of clones identified as mutants. Biallelic targeting efficiency for experiments 9 to 11 indicates percentage of clones containing large deletion alleles without the presence of wildtype alleles as detected by PCR genotyping. nd - not determined 


\section{Highlights:}

- A genome editing method using Cas 9 mRNA and crRNA:tracrRNA duplex for hPSCs

- Total targeting efficiency up to $85 \%$ in multiple genetic loci in various hPSC lines

- Biallelic targeting efficiency up to $70 \%$ in multiple loci in various hPSC lines 
(a) CONDIION-A (Co-lipofection)
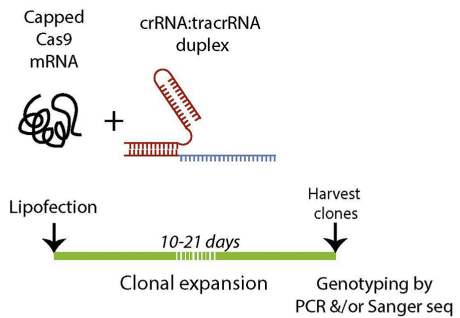

\section{CONDIIIN-B (Co-lipofection+selection)}
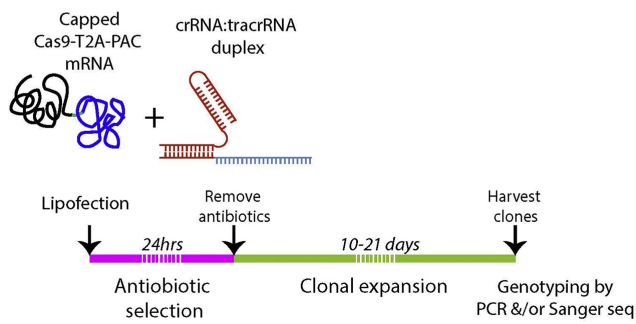

\section{CONDIION-C (Staggered lipofection+selection)}

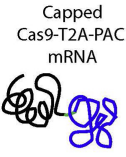

crRNA:tracrRNA duplex

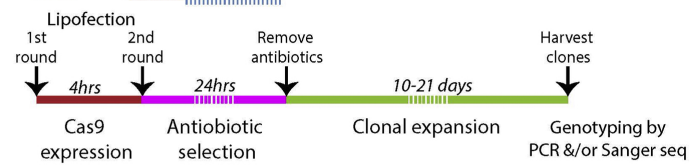

(e)

(g)

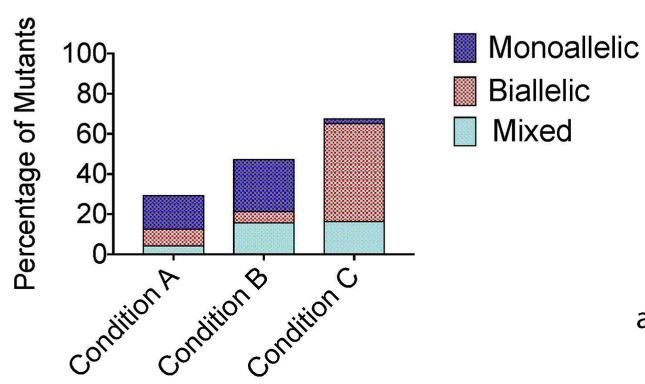

(f)

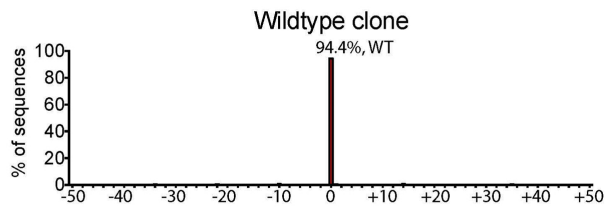

(d)

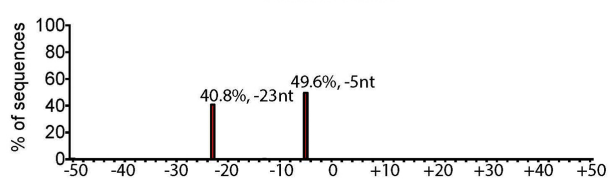

Monoallelic clone

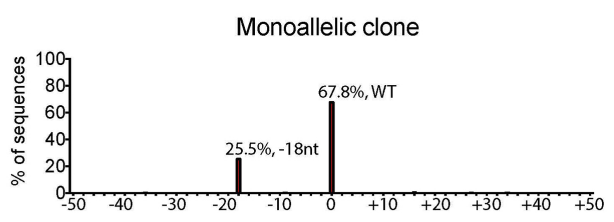

f) Mixed clone

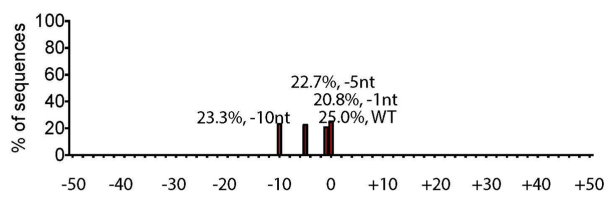

AFP locus

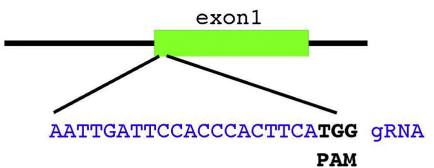

(c)

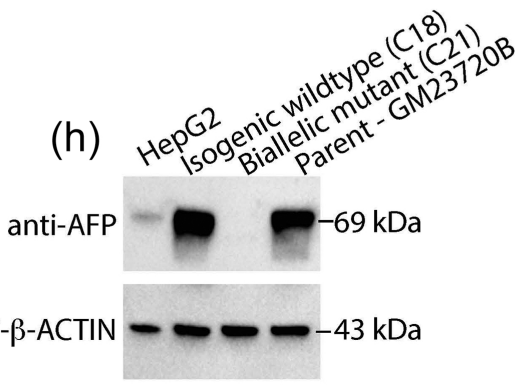


(a)

FOXB1 locus

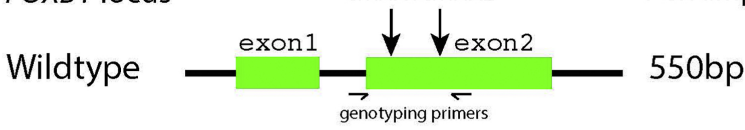

Knockout $\left[{ }_{-}^{\text {exon } 1}{ }_{-}^{\text {truncated exon2 }} 270 \mathrm{bp}\right.$

(b)

WA01 ES cells

$\begin{array}{lllllllllllllll}1 & 2 & 3 & 4 & 5 & 6 & 7 & 8 & 9 & 10 & 11121314 & 15 & 16 M & 171819202122 & 2324\end{array}$

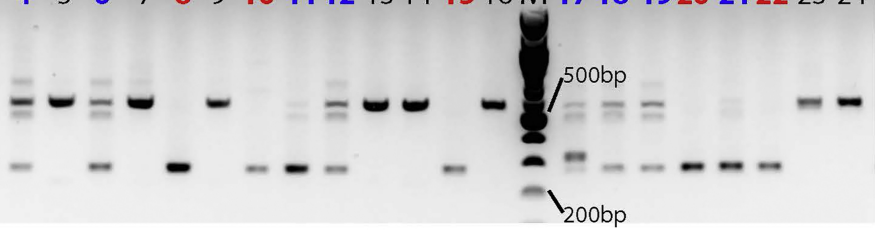

25262728293031323334353637383940 M 4142434445464748

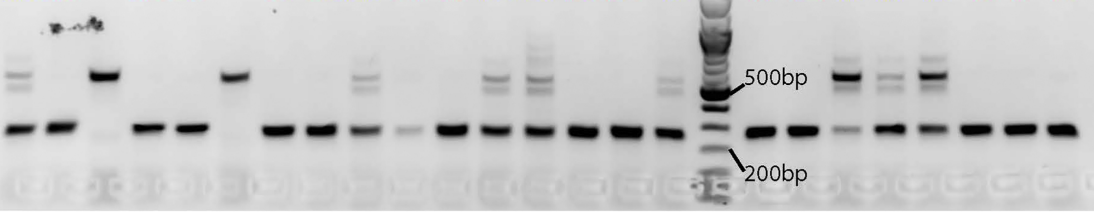

$49505152 \quad 53545556575859606162 \quad 6364 \quad M \quad 65 \quad 66 \quad 6768 \quad 6970 \quad 7172$

(c)

$123345667891011121314151617181920+M$

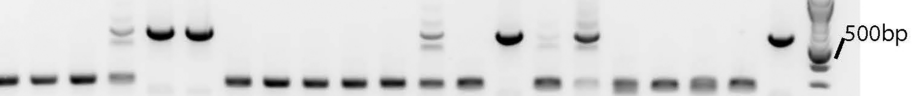

(e)

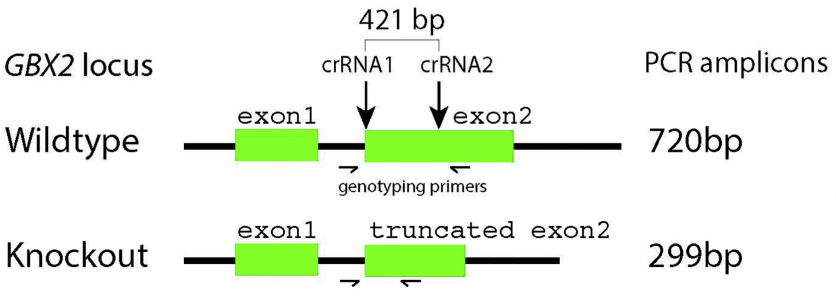

(f) WA01 ES cells

(d) Monoallelic deletion Biallelic deletions
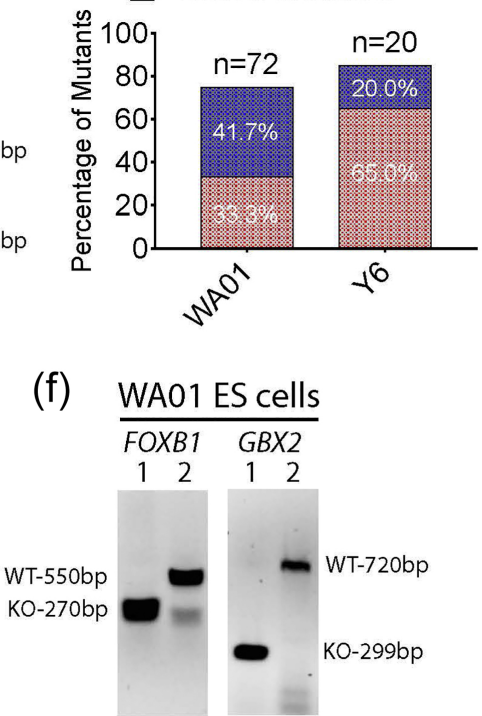